\title{
Onset of apoptotic DNA fragmentation can precede cell elimination by days in the small intestinal villus
}

\author{
Maria Pompeiano ${ }^{1,3}$, Massimo Hvala ${ }^{2}$ and Jerold Chun ${ }^{1,4}$ \\ ${ }^{1}$ Department of Pharmacology, School of Medicine, University of California, \\ San Diego, California, USA \\ 2 Via Cisanello n. 69, I-56124 Pisa, Italy \\ ${ }^{3}$ Dipartimento di Scienze dell' Uomo e dell'Ambiente, University of Pisa, Pisa, \\ Italy \\ ${ }^{4}$ corresponding author: Department of Pharmacology, Neurosciences \\ Program, School of Medicine, University of California, San Diego, 9500 Gilman \\ Drive, La Jolla, CA 92093-0636 tel: (619) 534 2659; fax: (619) 822 0041; \\ email: jchun@ucsd.edu
}

Received: 7.11.97; revised: 25.3.98; accepted: 2.4 .98

Edited by J. Cidlowski

\begin{abstract}
DNA fragmentation is a hallmark of apoptosis, and has been viewed as a short-lived process ( $<$ hour) that immediately precedes cell elimination. However, use of sensitive techniques like in situend-labelling plus (ISEL+) has indicated that the period between the initiation of detectable fragmentation and cell elimination could be longer (days). To address this possibility, we used a model system of cell death and replacement, the murine small intestinal villus. Pulses of 5bromo-2'-deoxyuridine were used to follow quantitatively cohorts of cells from their generation in the crypts to their elimination at the villus tips, resulting in a temporal 'yard-stick' where position on the villus indicated time before cell elimination; these data allowed a mathematical description of cell movement and clearance. Combining these data with ISEL+ quantitation, enterocytes were found to commence and maintain DNA fragmentation 2-3 days before elimination, a phenomenon that likely has relevance to studies on apoptosis also in other systems.
\end{abstract}

Keywords: apoptosis; crypt; DNA fragmentation; ISEL+; programmed cell death; small intestine; villus

Abbreviations: BrdU: 5-bromo-2'-deoxyuridine; ISEL+: in situendlabeling plus; PCD: programmed cell death; TUNEL: TdT-mediated dUTP-biotin nick end labeling

\section{Introduction}

Programmed cell death (PCD) is a biological process through which cells are eliminated in response to activation of an intrinsic genetic program (e.g. Kerr et al, 1972). Apoptosis is a type of PCD defined by characteristic morphological changes (Kerr et al, 1994) and by genomic DNA fragmentation at internucleosomal sites (Wyllie et al, 1984). It represents a common feature observed during developmental processes in multicellular systems (Ellis et al, 1991). During adult life, apoptosis may be associated with a number of pathological processes (Kerr et al, 1994) but has also been observed in normal tissues, where it appears to exert a homeostatic function. Apoptosis has been demonstrated in tissues showing fast (skin, gut, lymphatic tissues) as well as slow renewal (liver, pancreas, and kidney) (Gavrieli et al, 1992).

It is commonly believed that clearance time of apoptotic cells is in the range of hours (Raff et al, 1993). This may be viewed as a minimum time required to eliminate a DNAfragmented cell (Gavrieli et al, 1992; Blaschke et al, 1996), whereas the upper ranges of elimination times remain unknown, especially with the use of more sensitive techniques like in situ end labeling plus (ISEL+) (Blaschke et al, 1996; Chun and Blaschke, 1997). To estimate this latter value in vivo, a mammalian model of apoptosis, the mouse small intestinal villus, was examined. The villus and the associated crypt of Lieberkühn represent the anatomical and functional units of the small intestine (see Figure 1), and epithelial cells undergo continuous and rapid renewal in a geographically organized way (Gordon and Hermiston, 1994). In adult mice, multipotent stem cells are located at the base of each crypt where they undergo several rounds of cell division followed by differentiation into one of the four lineages: enterocyte, mucous (goblet) cell, enteroendocrine cell and Paneth cell. Paneth cells migrate and differentiate near the crypt base, where they are phagocytosed after a 20 day period. In contrast, the other three cell types differentiate and migrate from the crypt up to the villus tip over a 2-5 day period (e.g. Cheng and Leblond, 1974; Wright and Alison, 1984a) during which they apoptose (Gavrieli et al, 1992; Han et al, 1993; Hall et al, 1994; Iwanaga et al, 1994) and are extruded from the tip of the villus (Leblond and Messier, 1958; Potten and Allen, 1977; Wright and Alison, 1984b; Iwanaga et al, 1994; Shibahara et al, 1995).

These well documented proliferative and migratory parameters were used to determine two additional parameters: (1) the time following DNA synthesis at which detectable DNA fragmentation occurs; and (2) the period between this initial DNA fragmentation and the point at which cells were eliminated from the villus tip. From this analysis, we have determined that cells in vivo can commence DNA fragmentation up to several days before they are eliminated.

\section{Results}

Villus epithelial cells were counted for each animal following different analytical treatments as reported in Table 1. No attempt was made to distinguish amongst the different cell types in the villus epithelium (enterocytic, mucous or enteroendocrine cells), since enterocytes represent about $95 \%$ of the epithelial cells, mucous and enteroendocrine cells representing only about $4-5$ and $0.5-1 \%$ respectively of the 
villi epithelial cells in the mouse jejunum (Cheng and Leblond, 1974; Wright and Alison, 1984a). On the other hand, mucous and enteroendocrine cells appear to migrate at a slightly but not significantly different speed than the enterocytes (Wright and Alison, 1984a).

LUMEN

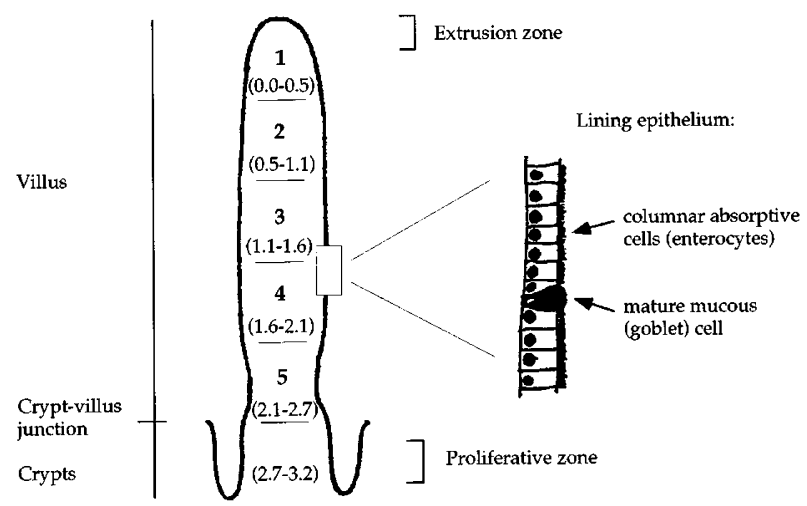

Figure 1 Schematic representation of the morphofunctional unit of the small intestine, the villus with the adjoining crypts, shown in longitudinal section. The proliferative zone, located in the crypts, is the areas where undifferentiated cells divide thus beginning epithelial renewal. Newly generated cells from this area generally migrate upward toward the villus to be eventually extruded into the gut lumen at the level of the extrusion zones at the villus tip. The villus is shown divided in five quintiles of equal length, numbered from 1-5 from the villus tip to the villus base. The inset shows at higher magnification the singlecell thick epithelium lining the villus. Only the most abundant cell types are represented: the columnar absorptive cells (about 95\%) and the mature mucose (goblet) cells (4-5\%). In parenthesis is the estimated mean life expectancy (in days) for cells in each villus quintile and in the crypt, as determined from the mathematical analysis of BrdU labeled cells data

Table 1 Animals used and labeled villi measured

\begin{tabular}{|c|c|c|c|c|c|}
\hline & \multirow[b]{2}{*}{$\begin{array}{l}\text { Animal } \\
\text { I.D.\# }\end{array}$} & \multicolumn{2}{|c|}{ ISEL+ } & \multicolumn{2}{|r|}{ BrdU } \\
\hline & & $\begin{array}{l}\text { No. of } \\
\text { labeled } \\
\text { villli }\end{array}$ & $\begin{array}{c}\text { Mean } \\
\text { length } \\
(\mu \mathrm{m} \pm \text { S.E.M. })\end{array}$ & $\begin{array}{l}\text { No. of } \\
\text { labeled } \\
\text { villi }\end{array}$ & $\begin{array}{c}\text { Mean } \\
\text { length } \\
(\mu \mathrm{m} \pm \mathbf{S . E . M . ~})\end{array}$ \\
\hline \multirow[t]{3}{*}{1 day } & 2 & 3 & \multirow[t]{3}{*}{$485 \pm 9$} & 3 & \multirow[t]{3}{*}{$466 \pm 12$} \\
\hline & 7 & 2 & & 4 & \\
\hline & 8 & 2 & & 3 & \\
\hline \multirow[t]{3}{*}{2 days } & 3 & 3 & \multirow[t]{3}{*}{$494 \pm 23$} & 3 & \multirow[t]{3}{*}{$489 \pm 9$} \\
\hline & 9 & 2 & & 3 & \\
\hline & 10 & 2 & & 4 & \\
\hline \multirow[t]{3}{*}{3 days } & 4 & 4 & \multirow[t]{3}{*}{$510 \pm 13$} & 4 & \multirow[t]{3}{*}{$490 \pm 11$} \\
\hline & 11 & 2 & & 3 & \\
\hline & 12 & 2 & & 3 & \\
\hline \multirow[t]{3}{*}{4 days } & 5 & 3 & \multirow[t]{3}{*}{$513 \pm 11$} & 4 & \multirow[t]{3}{*}{$513 \pm 13$} \\
\hline & 13 & 2 & & 3 & \\
\hline & 14 & 2 & & 3 & \\
\hline \multirow[t]{3}{*}{5 days } & 6 & 4 & \multirow[t]{3}{*}{$465 \pm 12$} & 5 & \multirow[t]{3}{*}{$488 \pm 11$} \\
\hline & 15 & 2 & & 3 & \\
\hline & 16 & 2 & & 2 & \\
\hline \multirow[t]{2}{*}{7 days } & 17 & 5 & \multirow[t]{2}{*}{$498 \pm 15$} & 4 & \multirow[t]{2}{*}{$517 \pm 15$} \\
\hline & 18 & 3 & & 2 & \\
\hline
\end{tabular}

A total of 45 villi were analyzed for ISEL+ and of 56 villi for BrdU incorporation

\section{Location of ISEL+ labeled cells along the villus length}

To determine the overall extent of dying cells, normal villi were labeled using ISEL+, and the number and position of labeled cells documented using video microscopy. No significant difference was observed in the distribution of ISEL+ labeled cells along the villus amongst time points (by three-way loglinear test, see Materials and Methods), eliminating the variable of the possible induction of apoptosis by 5-bromo2 '-deoxyuridine (BrdU) treatment. Data from all animals were pooled and statistically analyzed to calculate the means for total, labeled, and percentage of labeled cells in each quintile (Table 2). The percentage of ISEL+ labeled cells was highest (about $90 \%$ ) in the first quintile (the villus top, furthest in the intestinal lumen), and it progressively decreased along the villus to reach the lowest value (about $40 \%$ ) in the fifth, bottom quintile (Figure 2a). ISEL+ cell staining intensity within a labeled cell also appeared to decrease from quintile 1 to 5 . ISEL+ labeled cells and cellular debris were very abundant in the lumen, and labeled cells were often observed protruding from the villus tip (Figure 2d).

Labeled cells were also seen in the crypts and within the villus, either in subepithelial locations or more centrally along the villus axis (Figure 2a) and in parenchymal tissue between the crypts. These cells probably represent nonenterocyte lineages, most likely macrophages, lymphocytes and eosinophils.

\section{Relationship between cell age and position along the villus as determined by BrdU labeling of enterocytes}

To determine the age of enterocytes at different positions along the length of the villus, BrdU pulses were used to label premigratory cells within the crypts and their location along the villus identified by anti-BrdU immunohistochemistry at successive days after BrdU injection. The mean percentages of BrdU labeled cells in each villus quintile and for each time point were determined (Table 3). One day after the BrdU injection, BrdU-labeled cells were seen only in quintiles 4 and 5 (Figure $2 b$ ). After 3 days, cells initially reached quintile 1 (Figure 2c) where they could be detected for $4-5$ days with a concomitant decrease from quintiles $3-5$. By 7 days after BrdU injection, few labeled cells were detected along the villus, and all of these were located in quintile 1.

Table 2 Quantitation and location of villi epithelial cells labelled by ISEL+

\begin{tabular}{lccc}
\hline Quintile & $\begin{array}{c}\text { No. of } \\
\text { total cell }\end{array}$ & $\begin{array}{c}\text { No. of } \\
\text { labeled cell }\end{array}$ & $\begin{array}{c}\% \text { of } \\
\text { labeled cell }\end{array}$ \\
\hline 1 & $51.0 \pm 2.4$ & $46.7 \pm 2.3$ & $91.4 \pm 0.7$ \\
2 & $48.7 \pm 2.2$ & $38.2 \pm 1.6$ & $79.6 \pm 1.5$ \\
3 & $52.0 \pm 2.2$ & $35.2 \pm 1.7$ & $68.2 \pm 1.8$ \\
4 & $54.1 \pm 2.3$ & $30.8 \pm 1.8$ & $56.0 \pm 2.1$ \\
5 & $56.8 \pm 2.3$ & $21.8 \pm 1.8$ & $36.2 \pm 2.2$ \\
\hline
\end{tabular}

Percentage of ISEL+ labeled cells for each villus quintile ( $1=$ top or lumenal quintile, $5=$ =bottom quintile): data are pooled from mice sacrificed 1, 2, 3, 4, 5 and 7 days after BrdU injection ( $n=45)$. Data are \pm S.E.M. Mean villus length was $496 \pm 6 \mu \mathrm{m}$ 


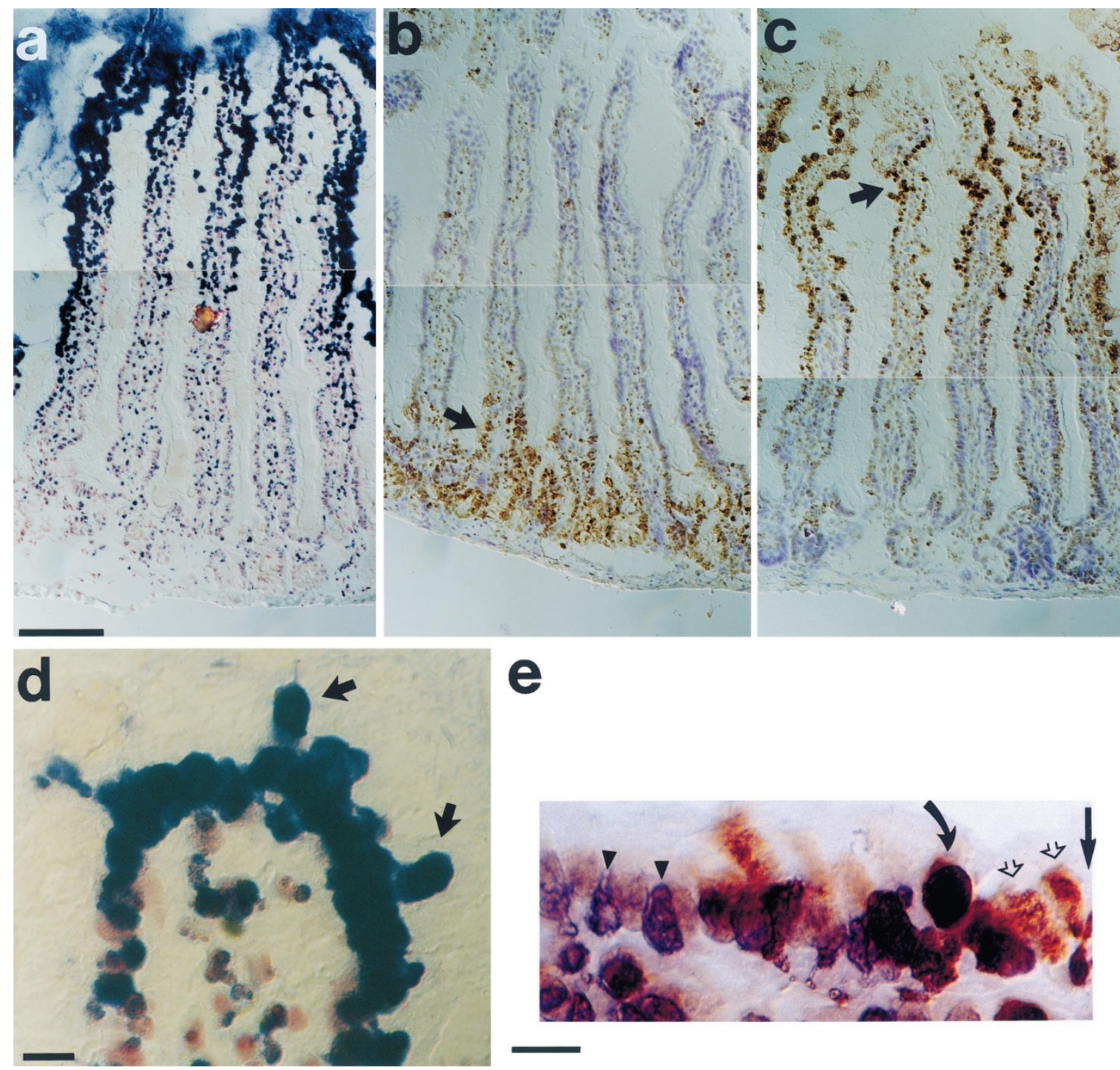

Figure 2 Examples of ISEL+ and BrdU labeling used for quantitative analysis in the small intestine. (a) ISEL+ detection of fragmented DNA reveals high levels of apoptosis in the small intestinal villi. Labeled cells appear dark blue. The section has been counterstained with Neutral Red (staining cells pink). (b) The position of 1 day old cells was identified with anti-BrdU immunohistochemistry, in a mouse sacrificed 1 day after BrdU injection. Labeled cells appear brown. The arrow points to the lower part of the villi, where strongly labeled cells are present in quintile 5. The section has been counterstained with Cresyl Violet. (c) In a mouse sacrificed 3 days after BrdU injection, anti-BrdU immunohistochemistry shows progression of labeled cells up the villus. The arrow points to quintile 2 of the villi, where the highest percentages of labeled cells are observed. (d) High magnification of the tip of a villus labeled with ISEL+: arrows point to apoptotic cells which are being extruded from the villus tip. (e) High magnification of the epithelium lining the base of a villus (quintile 5) from a mouse sacrificed 1 day after BrdU injection. The vertical straight arrow on the right shows the level of the crypt-villus junction: the crypt is on the right side of it (out of the photographic field) and the villus tip towards the left. The villus was double-labeled for ISEL+ and BrdU. Arrowheads point to cells labeled by ISEL+ only (violet), empty arrows point to cells labeled with BrdU only (brown), and curved arrow points to one of several ISEL+-BrdU double-labeled cell in the field. Bar, $100 \mu \mathrm{m}(\mathbf{a}, \mathbf{b}, \mathbf{c})$ and $10 \mu \mathrm{m}(\mathbf{d}, \mathbf{e})$

Table 3 Quantitation and location of BrdU labeled epithelial cells in villi examined at successive days after BrdU injection

\begin{tabular}{lcccccc}
\hline Quintile & $\begin{array}{c}\mathbf{1} \text { day } \\
(\boldsymbol{n}=\mathbf{1 0})\end{array}$ & $\begin{array}{c}\mathbf{2} \text { days } \\
(\boldsymbol{n}=\mathbf{1 0})\end{array}$ & $\begin{array}{c}\text { 3 days } \\
(\boldsymbol{n}=\mathbf{1 0})\end{array}$ & $\begin{array}{c}\mathbf{4} \text { days } \\
(\boldsymbol{n}=\mathbf{1 0})\end{array}$ & $\begin{array}{c}\mathbf{5} \text { days } \\
(\boldsymbol{n}=\mathbf{1 0})\end{array}$ & $\begin{array}{c}\mathbf{7} \text { days } \\
(\boldsymbol{n}=\mathbf{6})\end{array}$ \\
\hline 1 & $0.4 \pm 0.4$ & $1.3 \pm 0.8$ & $64.2 \pm 5.5$ & $64.3 \pm 5.3$ & $56.8 \pm 7.4$ & $4.9 \pm 1.2$ \\
2 & $0.9 \pm 0.7$ & $2.8 \pm 1.8$ & $73.9 \pm 3.7$ & $48.1 \pm 5.1$ & $42.2 \pm 6.5$ & $2.0 \pm 0.5$ \\
3 & $1.2 \pm 0.5$ & $33.8 \pm 4.4$ & $61.8 \pm 3.7$ & $35.1 \pm 2.6$ & $26.5 \pm 5.0$ & $2.3 \pm 1.1$ \\
4 & $20.6 \pm 3.1$ & $65.0 \pm 4.0$ & $41.0 \pm 3.8$ & $24.3 \pm 4.1$ & $20.2 \pm 4.5$ & $1.3 \pm 0.5$ \\
5 & $60.3 \pm 2.8$ & $59.6 \pm 4.4$ & $22.4 \pm 3.2$ & $14.6 \pm 2.5$ & $11.4 \pm 3.0$ & $0.7 \pm 0.3$ \\
\hline
\end{tabular}

Percentage of BrdU labeled cells for each villus quintile in mice sacrificed 1, 2, 3, 4, 5 and 7 days after BrdU injection. Data are expressed as \% \pm S.E.M. 


\section{Kinetic parameters of cell migration}

To describe quantitatively the progression of BrdU-labeled enterocytes from villus crypts to tip (i.e., from quintile 5 quintile 1), a simple, 4-parameter equation was derived to fit the experimentally determined values of enterocyte movements (see Materials and Methods). Three of the four parameters have biological correlates: $c$ is the mean epithelial cell velocity along the intestinal villus, $z$ is the mean 'crypt depth' and a is the mean percentage of maximal labeling of cells moving towards the villus tip. The last parameter is B. From this analysis, the following values ( \pm S.D.) were obtained for the four parameters: $\mathrm{c}=184 \pm 23 \mu \mathrm{m} /$ day, $\mathrm{z}=94 \pm 48 \mu \mathrm{m}, \quad \mathrm{a}=76.9 \pm 8.3 \%$, and $B=790 \pm 150 \mu \mathrm{m}$. Note that $\mathrm{z}$ is not the actual anatomical 'crypt depth', because some cells undergo mitosis above the crypt base, and their migration is delayed by about $2 \mathrm{~h}$ because they must proceed through G2 phase and mitosis after incorporating BrdU (or after DNA synthesis), during $\mathrm{S}$ phase (Caimie et al, 1965; Cheng and Leblond, 1974). In contrast, $\mathrm{z}$ is the distance the cells would cover if they began migration soon after BrdU injection (or after DNA synthesis) with a speed equal to $c$. The ratio of $z / c=0.5$ day and is the actual mean time necessary for cells to reach the villus base after BrdU injection (or after DNA synthesis).

Epithelial cells of the villi population thus take 2.7 days to migrate from the bottom to the tip of villus (mean villus length $L=496 \mu \mathrm{m}, \mathrm{L} / \mathrm{c}=2.7$ days). Since 0.5 day is the mean time required by newly born cells to reach the villus base, 3.2 days is the total time necessary for a cell to migrate from the crypt to the villus tip. The mean time necessary for cells within each quintile to reach the tip of the villus and be eliminated is reported in Figure 1.

\section{Kinetics of elimination for ISEL+-BrdU double-labeled cells}

To determine the relationship between BrdU-labeled enterocytes and the presence of DNA fragmentation as detected by ISEL+, cells were double-labeled for ISEL+ and BrdU in villi from mice sacrificed 1 day after BrdU injection. Many cells were double-labeled within the lowest quintile (quintile 5) containing the youngest enterocytes within the villus (Figure $2 e)$, thus demonstrating that even 1-day old cells in the villi can commence DNA fragmentation.

Double-labeling experiments were also conducted on villi from mice sacrificed 2, 3, 4, 5 and 7 days after BrdU injection. Although no attempt was made to quantify this phenomenon, double-labeled cells clearly moved up the villus, following the movement of BrdU labeled cells. The proportion of BrdU cells which were also ISEL+-positive clearly increased with cell age, and represented the great majority by day 3 .

\section{Discussion}

DNA fragmentation associated with apoptosis has been reported in in vitro studies to be a short-lived state of a few hours or less, that immediately precedes cell elimination (Raff et al, 1993). In contrast, studies using a variety of histological techniques to examine apoptosis within intact tissues has suggested that dying cells can persist for days before a cell is actually eliminated (e.g., Hu et al, 1997). We thus examined the relationship between the onset of DNA fragmentation and cell elimination in the well-defined, model system of the epithelium of the murine small intestinal villus. We used ISEL+, a DNA end-labeling protocol that is $10 \times$ more sensitive than TUNEL (Blaschke et al, 1996; Chun and Blaschke, 1997) and whose detection limit is around 3000 double-strand breaks/nucleus (Chun and Blaschke, 1997), an extent of DNA fragmentation that is not compatible with a viable, mammalian cell (Dugle et al, 1976). Combining ISEL+ and BrdU labeling to follow cohorts of epithelial cells defined by birthdate, our results suggest that cells can commence DNA fragmentation on the villus days before they are actually eliminated.

A key feature of the small intestinal villus is that the entire population of epithelial cells is renewed every 2-5 days (e.g., Cheng and Leblond, 1974; Wright and Alison, 1984a). This feature enables a cohort of cells, identified by brief exposure to ${ }^{3} \mathrm{H}$-thymidine or BrdU, to be followed over time from their birth in the intestinal crypts, through their elimination at the tips of the villus several days later. The overwhelming majority of studies demonstrate that cell elimination occurs mainly from the tips of villi (e.g., Leblond and Messier, 1958; Potten and Allen, 1977; Iwanaga et al, 1994; Shibahara et al, 1995).

\section{Potential sources of error}

A potential source of error was the combination of ISEL+ with BrdU immunohistochemistry, the latter procedure utilizing DNA denaturation that could itself generate strand breaks. However, ISEL+ histochemistry always preceded BrdU immunostaining in our protocol. Further, villi from unmanipulated mice produced the same ISEL+ pattern as those from mice exposed to BrdU (data not shown), demonstrating that DNA fragmentation is due to intrinsic rather than artifactual processes.

Another potential source of error was the physical isolation of the small intestine, since damage could have been produced by surgical manipulation. However, care was taken to remove and immediately freeze tissue samples and only regions of tissues untouched and away from any instrumentation were examined. Yet another source of error was the actual tissue sectioning and subsequent processing. However this was controlled by the presence, in the same sectioned block as the intestine, of positive (embryonic brain) and negative (adult liver) controls, to ascertain that spurious DNA strand breaks were not produced by tissue processing. These controls were complemented by the invariant extent of ISEL+ labeled cells within villi. Labeling was always most intense at the villus tips and decreased in a graded fashion towards the crypts, indicating that DNA fragmentation did not occur to the same extent in all cells, as would be observed in artifactual conditions. Moreover, ISEL+ has been characterized as recognizing dying cells in a variety of other systems (Blaschke et al, 1996; Chun and Blaschke, 1997; Staley et al, 1997). Thus, DNA fragmentation observed here is due to normal biological processes and not to introduced errors. 


\section{BrdU and ISEL+ labeling is consistent with prior studies}

The kinetics of cell generation and elimination has been extensively examined in the small intestinal villus (e.g., Wright and Alison, 1984b), and the progression of BrdU labeled cells documented here is in complete agreement with prior studies in which a cohort of labeled cells was generated and then shown to migrate away from the crypts to be eliminated from the villus tip over a period of several days. Similarly, the highest extent of cell death, as revealed by ISEL+ labeling occurs at the tip, which has also been previously documented. The presence of ISEL+ labeled profiles and cellular debris in the lumen is consistent with previous findings (Han et al, 1993).

Prior studies have directly addressed the extent of DNA fragmentation using either TUNEL (Gavrieli et al, 1992; Shibahara et al, 1995) or another technique referred to as 'ISEL' (e.g., Ansari et al, 1993; Hall et al, 1994). These studies contrast with one another in that the extent of labeling observed with TUNEL was observed to extend partially down the villus from the tip, whereas 'ISEL' was found to label cells only at the villus tip. Our data extend the TUNEL observations by identifying cells further down the villus, with a decreasing labeling intensity from the tip to the base of the villus. This is not surprising in view of the approximately $10 \times$ increased sensitivity of ISEL+ over TUNEL. By contrast, the use of 'ISEL' produced a far more limited picture of DNA fragmentation (Hall et al, 1994). This is at odds (1) with data indicating that the entire villus epithelium turns over in a few days (Leblond and Messier, 1958; Cheng and Leblond, 1974; Wright and Irwin, 1982; Wright and Alison, 1984a; Collins et al, 1989; Ferraris et al, 1992) and (2) with an independent means of estimating the extent of apoptosis - ligation-mediated PCR amplification of DNA ladders - which indicates that the small intestine has by far the highest degree of DNA fragmentation compared to any adult tissue (Staley et al, 1997). It is of note that 'ISEL' could reveal a pattern similar to what we have observed here, with cells labeled into the lower quintile of the villus (Hall et al, 1994), but the pattern was attributed as an artifact of tissue preparation (delayed fixation). This explanation, however, can not explain why the 'artifactual increase' in labeling was limited to only the villi but did not extended into the crypts or surrounding muscle layers, as would be expected for a generalized degradation of unfixed tissue. A reinterpretation of these data in view of our report is that increased labeling after delayed fixation reflected either the normal, increased fragmentation of DNA in apoptosing - but not in non-apoptosing - cells, or that delayed fixation produced a tissue preparation with greater access to free DNA ends using the employed end-labeling technique.

\section{ISEL+ detectable cells exist from hours to days before elimination}

Our mathematical analysis of BrdU labeling data employed a non-linear regression to fit a function modeling the drift of cell cohorts. Particular emphasis was placed on appropriate statistical methods. We applied a non-standard $\chi^{2}$ test for data from at least 5 days to obtain the cell migration rate along the villi, while the data from the 7th day after BrdU injection were especially useful for monitoring cell disappearance. Previously reported methods for measuring the rate of cell migration analyzed the movement of the ${ }^{3} \mathrm{H}$-thymidine-labeled cells present at the most luminal position along a villus (the 'front edge' of the population) (Collins et al, 1989; Ferraris et al, 1992), which can have a maximal duration of at most 2-3 days. By comparison, our method analyzes cells over at least a 5 day period which is likely to provide increased accuracy over previous studies.

In our preparation, the mean cell speed along the villus was $184 \mu \mathrm{m} /$ day. This means that, in our villi population (with a mean length of about $500 \mu \mathrm{m}$ ), cells in the top 2 quintiles (approximately $200 \mu \mathrm{m}$ ), which also show a stronger ISEL+ staining intensity than other quintiles, will be eliminated in 1 day. The mean crypt and villus transit times were 0.5 and 2.7 days, respectively, in accordance with data from the literature (Cheng and Leblond, 1974; Wright and Irwin, 1982; Collins et al, 1989; Ferraris et al, 1992). In double-labeling experiments, we demonstrated that BrdU and ISEL+ labeled cell populations at least partly overlap in the lowest quintile of mice sacrificed 1 day after BrdU injection. Since it requires a mean of $2.1-2.7$ days for these cells to reach the tip of the villus and since cell loss occurs predominantly at the villus tip (Leblond and Messier, 1958; Potten and Allen, 1977; Wright and Alison, 1984b; Iwanaga et al, 1994; Shibahara et al, 1995), our results indicate that apoptotic cells, as detected by ISEL+ techniques, can persist in the intestinal villi for periods up to 2-3 days, depending on their position (quintile) along the villus. These estimates of cell clearance are in good accordance with indirect determinations of another postmitotic population, the granule cells of the rat hippocampus, examined in adrenalectomized rats ( $\mathrm{Hu}$ et al, 1997).

These results are in contrast with the common belief that clearance times of apoptotic cells are in the range of an hour (Raff et al, 1993). However, we note that differences clearly exist amongst differing cell types; for example enucleated erythrocytes live for weeks (Berlin and Berk, 1975), while O-2A cells in culture exist for an hour, once they appear pyknotic (Barres et al, 1992). We speculate that cells removed rapidly (hours) are either actively proliferating (e.g. cells in culture) or are in the end stages of apoptosis (e.g. analogous to cells in quintile 1 of the villus). By contrast, cells initiating DNA fragmentation (e.g., cells in quintile 5) as detected by more sensitive means like ISEL+ have increased clearance times whereby an identified cell may persist for several days before elimination.

\section{Possible roles for transient but functional cells}

Based on our data, villus epithelial cells irreversibly commit to die soon after they are generated, and this is consistent with prior studies demonstrating that cells gradually lose normal gene regulation as they migrate to the villus tip (Ferraris and Diamond, 1992). Despite this commitment to death, cells remain functional as they migrate along the villus, where nutrient absorption processes occur. Indeed, physiological 
studies have demonstrated that enterocytes most active in absorption are those from the upper third (quintiles 1-2) of the jejunal villi (e.g., Wright et al, 1994), and this biology is reminiscent of mammalian erythrocytes that function without a nucleus. In the intestine, this mechanism could serve to minimize risks associated with exposure to chemicals present in the diet (Vaux, 1993). Cells committed to die could provide a protective barrier through which toxic substances are neutralized without risk of viable genomic mutations. This may in part explain the low incidence of cancer in the small intestine (Potten et al, 1994). The mechanisms controlling this phenomenon are not known, but may involve a form of apoptosis called 'anoikis' induced by the disruption of cellmatrix interactions (Frisch and Francis, 1994).

The maintenance of functionality in cells committed to die may have roles in other tissues and may have particular relevance to developing systems. ISEL+ was first used to study embryonic brain development where it identified a surprising degree of apoptosis (Blaschke et al, 1996). From data presented here, we suggest that an analogous timecourse of elimination also occurs for cells within the embryonic brain ranging from hours to days during which a cell could maintain some degree of functionality. This mechanism of generating cells with finite functionality limited by imminent cell death could provide a transient template for the organization of surviving cells in a variety of developing tissues.

\section{Materials and Methods}

\section{BrdU injection and tissue collection and preparation}

A total of 23 adult male Balb/c mice (aged 3 months, 25-30 g, Harlan Sprague Dawley) were used: 17 mice were used for ISEL+ and BrdU single labeling, and additionally, were combined with six mice for double-labeling studies (total of 23). The mice were injected IP with $20 \mu \mathrm{l} / \mathrm{g}$ body weight of $10 \mathrm{mM} \mathrm{BrdU}$ (Sigma, St Louis, MO) in saline and sacrificed by cervical dislocation 1, 2, 3, 4, 5 and 7 days after the injection (17 mice: $n=3$ for each time point, except $n=2$ for 7 days). All injections were performed and all animals were killed at 4 PM ( $\pm 30 \mathrm{~min}$ ) to avoid variation associated with circadian rhythms (Potten et al, 1977). The small intestine was quickly removed in its entirety, from the pylorus to the ileo-coecal junction. The ileum was usually macroscopically distinguishable from the jejunum for its darker color. Only the first, more proximal part of the jejunum was used for these experiments. The desired tissues were rapidly cut out, embedded in Tissue-Tek (Fisher Scientific, Pittsburgh, PA) and frozen in dry ice. The duodenum was recognized microscopically for the presence of Brunner glands. Sections were cut at $10 \mu \mathrm{m}$ on a cryostat (Jung Frigocut 2800E) and collected on charged glass slides. Sections were immediately thaw-dried and fixed in $4 \%$ paraformaldehyde, extracted with $0.6 \%$ Triton X-100 (Sigma) in $2 \times$ SSPE and acetylated. Sections were dehydrated through graded ethanols and used immediately or stored at $-80^{\circ} \mathrm{C}$.

\section{Detection of programmed cell death- ISEL+}

The presence of cells undergoing PCD was determined by using ISEL+, performed as described previously (Blaschke et al, 1996). Sections were incubated for $1 \mathrm{~h}$ in labeling mix (100 mM potassium cacodylate, $2 \mathrm{mM} \mathrm{CoCl}_{2}, 0.2 \mathrm{mM}$ DTT, $0.5 \mu \mathrm{M}$ digoxigenin-11 -dUTP (Boehringer-Mannheim, Indianapolis, IN) containing $150 \mathrm{U} / \mathrm{ml}$ terminal deoxynucleotidyl transferase (TdT, Boehringer-Mannheim). Incorporated digoxigenin-11 -dUTP was detected by an overnight incubation with alkaline phosphatase-conjugated anti-digoxigenin Fab fragment (Boehringer-Mannheim) at a dilution of 1:500. Alkaline phosphatase activity was detected by incubation in substrate solution (100 mM Tris, $100 \mathrm{mM} \mathrm{NaCl}, 50 \mathrm{mM} \mathrm{MgCl} 2, \mathrm{pH} 9.5)$ containing $450 \mu \mathrm{g} / \mathrm{ml} \mathrm{4-}$ nitroblue tetrazolium chloride (NBT, Boehringer-Mannheim) and $17.5 \mu \mathrm{g} / \mathrm{ml}$ 5-bromo-4-chloro-3-indolyl phosphate (BCIP, BoehringerMannheim). Color was allowed to develop for about $10 \mathrm{~min}$. After washing, sections were counterstained with Neutral Red (1\% in Milli-Q $\mathrm{H}_{2} \mathrm{O}$, for $2 \mathrm{~min}$ ), rapidly washed and dehydrated through graded ethanols and xylene and mounted in Cytoseal 60 (Stephens Scientific, Riverdale, NJ). Slides were then immediately examined and photographed using a Zeiss microscope.

The main differences between ISEL+ and other end-labeling techniques have already been described (Chun and Blaschke, 1997). Briefly, the increased sensitivity of ISEL+ is due to the tissue preparation, the use of digoxygenin-dUTP (instead of biotinylated deoxynucleotides), the incubation with the anti-digoxigenin antibody which is carried on overnight (instead of the usual $1 \mathrm{~h}$ ) and the visualization through an alkaline phosphatase reaction giving a bluish reaction product (instead of a peroxidase reaction).

\section{BrdU labeling}

For detection of cells incorporating BrdU, sections were incubated at $65^{\circ} \mathrm{C}$ in a solution of $50 \%$ formarmide $/ 2 \times \mathrm{SSC}$ overnight to denature DNA, washed in $2 \times S S C$ and incubated at $37^{\circ} \mathrm{C}$ in $2 \mathrm{~N} \mathrm{HCl}$ for $30 \mathrm{~min}$. Sections were then neutralized in $0.1 \mathrm{M}$ boric acid, $\mathrm{pH} 8.5$, washed in PBS and blocked in 2.5\% BSA/0.3\% Triton X-100/PBS, pH 7.5 for $1 \mathrm{~h}$. They were then incubated with a mouse monoclonal anti-BrdU antibody (Boehringer-Mannheim) at a concentration of $3 \mu \mathrm{g} / \mathrm{ml}$ in the same blocking solution overnight. Sections were then washed in PBS and bound antibody was detected with biotinylated anti-mouse IgG and an ABC-HRP kit (Vector Labs, Burlingame, CA) and 3,3' diaminobenzidine (DAB, Sigma) as the chromogen. Color was allowed to develop for 5-15 min. After washing, sections were lightly counterstained with Cresyl Violet $\left(0.5 \%\right.$ in Milli-Q $\mathrm{H}_{2} \mathrm{O}$, for $\left.30 \mathrm{~s}\right)$, rapidly washed and dehydrated through graded ethanols and xylene and mounted in Cytoseal 60. Slides were then immediately examined and photographed using a Zeiss microscope.

\section{Double-labeling with ISEL+ and BrdU}

Double-labeling was performed by integrating the BrdU and ISEL+ detection protocols. ISEL+ procedures always preceded BrdU detection, eliminating the artifactual production of DNA strand breaks. Sections were end-labeled according to the ISEL+ protocol and then incubated in $50 \%$ formamide/ $\times$ SSC at $65^{\circ} \mathrm{C}$ overnight. They were washed in $2 \times$ SSC and the ISEL+ protocol was completed by incubation with anti-digoxigenin Fab fragments followed by the colorimetric detection. Sections were then transferred to $2 \mathrm{~N} \mathrm{HCl}$, neutralized, and the BrdU detection protocol was completed as described above. Sections were finally rinsed in water, mounted in Crystal/mount (Biomeda Corp., Foster City, CA), and examined and photographed using a Zeiss microscope.

\section{Villi selection and cell counting}

For each time point, and for each labeling technique, villi were identified which showed a typical cylindrical shape and a similar length 
(mean length \pm S.E.M. for ISEL + was $496.4 \pm 6.4 \mu \mathrm{m}$ with $n=45$ and for BrdU 492.6 $\pm 5.1 \mu \mathrm{m}$ with $n=56$; range $409-560 \mu \mathrm{m}$ ) at their maximal height identified analyzing consecutive sections. We have limited our studies to a homogeneous population of villi from the first part of the jejunum, since villi length and kinetics vary significantly along the length of the small intestine (Wright and Irwin, 1982). The number of total and labeled cells of the epithelium lining the selected sectioned villi from crypt-villus junction to villus tip (villus row count, Wright and Irwin, 1982) was counted, and the percentages of labeled cells determined in the selected villi at their maximal height. Each villus was divided into five regions of equal length and the distribution of total and labeled cells was expressed in quintiles, numbered from the top to the bottom of the villus. No attempt was made to distinguish among the different epithelial cell types of the villus, since $95 \%$ of them are represented by enterocytes (Cheng and Leblond, 1974; Wright and Alison, 1984a).

\section{Mathematical analysis}

The model We assumed that cell migration along villus is similar to a flow where cell cohorts move regularly in one direction without mixing. For simplicity we also assumed that cell loss occurs only at the extrusion zone at the tip of the villus. There may indeed be some cell loss from the villus sides and possibly also from the crypt-villus junction, but the major cell loss occurs from the villus tip extrusion zone (Wright and Alison, 1984b). BrdU blood concentration decreases rapidly after injection (Kriss and Revesz, 1961) so that it can be modeled by a very narrow distribution centered at time $t=0$. The crypts absorb BrdU rapidly and after absorption BrdU concentration in the cells of the crypts decreases because the tracer is diluted in the proliferating epithelium and post-mitotic cells migrate up the villus. In this way, BrdU concentration profile should be exponentially rising through the villus up to the location of the first cells that were born at tracer administration. Cells beyond this point along the villus should not contain BrdU because they were generated before BrdU injection (see Figure 3a). However, our data are expressed as labeled cell percentages rather then BrdU concentration. For all values of BrdU concentration greater than a certain value, all cells are always labeled (100\% labeled cells). Those cells with a concentration lower than a threshold concentration are instead undistinguishable from cells without BrdU. Between these two limits the number of labeled cells should be related to BrdU concentration. We assumed that in this range the relation between tracer concentration and labeled cell percentage is linear. Figure $3 b$ shows the same BrdU concentration function of Figure $3 a$ (thin line) with superimposed the corresponding percentage function (thick line). Finally, Figure $3 c$ shows the actual function we used: from a computing point of view, it is an advantageous simplification of the thick profile of Figure $3 \mathrm{~b}$. The coherent flow of the cells is easily described by a wave shaped like that of Figure $3 \mathrm{c}$. Therefore the model of labeled cell percentages versus $\mathrm{x}$ (the distance from villus base) and versus $\mathrm{t}$ (the time since BrdU administration) can be a function $f$ of $x, t$, and four additional parameters, including the velocity of cell migration along the villus, $c$, and the 'crypt depth' $z$ (this is not the real anatomical crypt depth, but is the mean distance cells would go if they would start moving soon after $\mathrm{BrdU}$ injection with velocity $=\mathrm{c}$ ).

Parameter estimation Our experimental data are the percentages, in each quintile, of labeled cells compared to total ones. These values are integral averages inside the quintile, so we want to approximate by the least squares method 280 (the total number of quintiles $=5$ quintiles/villus $\times 56$ villi measured) integrals of our model function, tuning the parameters. A tolerance is associated to each datum, which

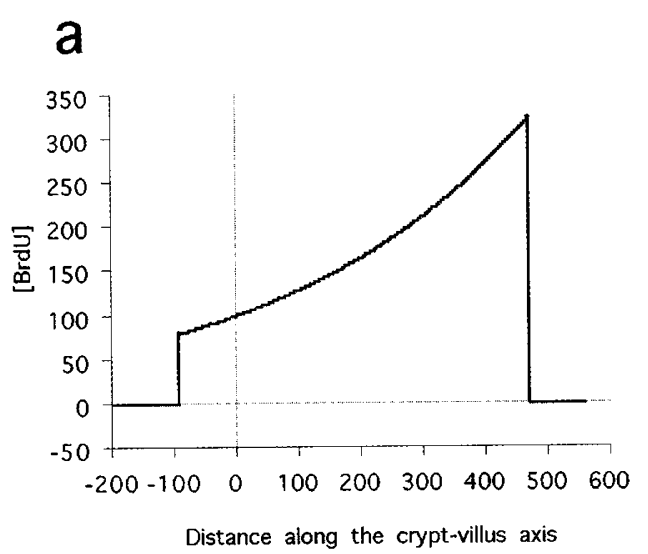

b
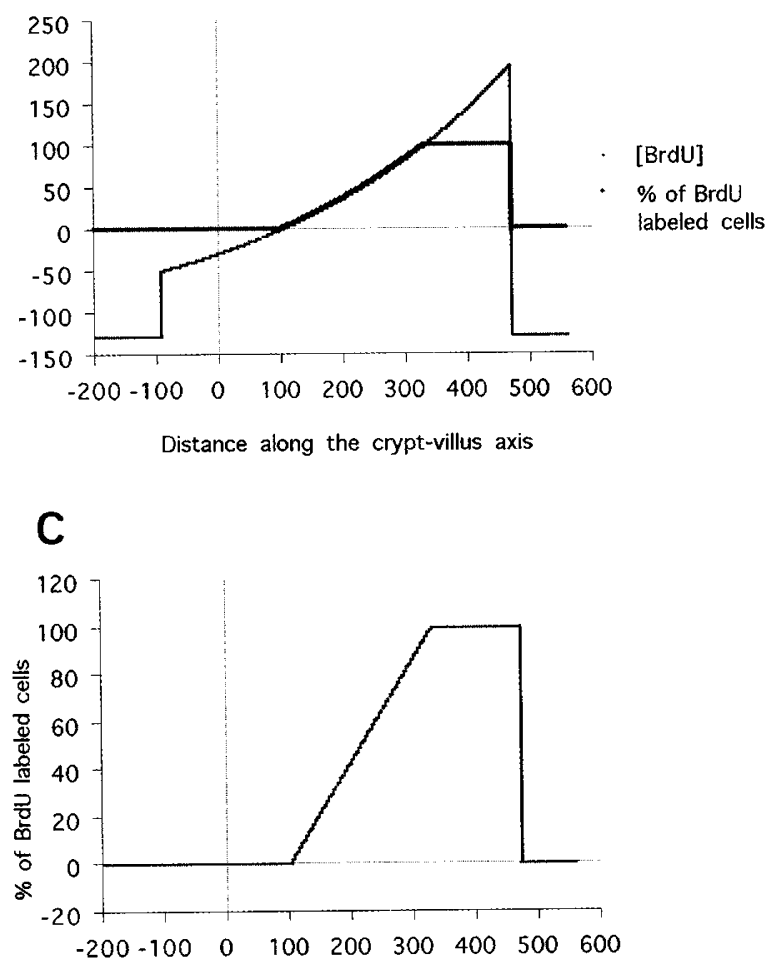

Distance along the crypt-villus axis

Figure 3 Graphical representation of the model used for the mathematical analysis of cell migration along the villus as detemined by BrdU labeling which was used to estimate the clearance time of ISEL+ labeled cells. (a) Ideal profile of dilution of BrdU concentration (in arbitrary units) produced by multiple cell divisions in cells that have subsequently migrated up along the crypt-villus axis. 0 represents the crypt-villus junction; negative values refers to the crypt and positive values to the villus. The peak value of the curve represents cells that have been maximally labeled by BrdU and have migrated to the villus tip (about $500 \mu \mathrm{m}$ ). Trailing cell populations reflect the exponential decrease in BrdU concentration within these cells produced by successive rounds of mitosis before following the heaviest labeled population of cells up the villus. (b) Modifications to the ideal curve that take into account the collected data expressed as BrdU labeled cell percentages along the cryptvillus axis (thick line). This modified curve can be superimposed on the BrdU concentration profile (thin line, the same as in a). The flattened peak and tail reflect experimental maxima and minima (see Materials and Methods). (c) BrdU labeled cell percentages along the crypt-villus axis adjusted for changes shown in $b$, fitted by a straight line 
depends, above all, on villi variableness in the intestine and on the animal. Villus lengths, and so villus quintiles, generally are different for different villi and we cannot estimate experimental data tolerances by standard deviations. So we would not be able to calculate good parameter values and it would be impossible to state parameter precisions because we can not use the standard $\chi^{2}$ algorithm. We decided then to address the problem in a different way. We considered only one villus for each day: in this case we have 30 integral relations to estimate the parameters. We performed again and again this calculation for all possible combinations of six villi, one per day (with our data, the combination set has six hundred thousand elements). In this way, we obtained a large set of values for each parameter. Each value has a weighting factor given by its $1 / \chi^{2}$ value and with a weighted average we can calculate the most probable parameter value. It is also easy to find parameter standard deviation from the same set of values and weights. The obtained values and their tolerances would thus be independent from experimental data precision and would be very accurate.

\section{Acknowledgements}

We wish to thank Anne Blaschke for technical advice, Carol Akita for technical help, Evan Balaban for help with the statistical analysis, and Joshua Weiner for critically reading the manuscript. This work was supported by the Tobacco-Related Disease Research Program, 61T0239.

\section{References}

Ansari B, Coates PJ, Greestein BD and Hall PA (1993) In situ end-labelling detects DNA strand and breaks in apoptosis and other physiological and pathological states. J. Pathol. 170: 1-8

Barres BA, Hart IK, Coles HSR, Burne JF, Voyvodic JT, Richardson WD and Raff MC (1992) Cell death and control of cell survival in the oligodendrocyte lineage. Cell 70: $31-46$

Berlin NI and Berk PD (1975) The biological life of the red cell. In: The Red Blood Cell, Surgenor DM, (ed) New York: Academic Press pp. 957-1019

Blaschke AJ, Staley K and Chun J (1996) Widespread programmed cell death in proliferative and postmitotic regions of the fetal cerebral cortex. Development 122: $1165-1174$

Cairnie AB, Lamerton LF and Steel GG (1965) Cell proliferation studies in the intestinal epithelium of the rat. II. Theoretical aspects. Exp. Cell Res. 39: 539553

Cheng $\mathrm{H}$ and Leblond CP (1974) Origin, differentiation and renewal of the four main epithelial cell types in the mouse small intestine. I. Columnar cell. Am. J. Anat. 141: $461-480$

Chun J and Blaschke AJ (1997) Identification of neural programmed cell death through the detection of DNA fragmentation in situ and by PCR. In: Current Protocols in Neuroscience, Chanda VB and Crooks GP, (eds) New York: John Wiley and Sons pp. 3.8.1-3.8.19

Collins AJ, James PS and Smith MW (1989) Sugar-dependent selective induction of mouse jejunal disaccharidase activities. J. Physiol. (Lond.) 419: 157-167

Dugle DL, Gillespie CJ and Chapman JD (1976) DNA strand breaks, repair, and survival in x-irradiated mammalian cells. Proc. Natl. Acad. Sci. USA 73: 809-812

Ellis RE, Yuan J and Horvitz HR (1991) Mechanisms and functions of cell death. Annu. Rev. Cell Biol. 7: 663-698

Ferraris RP and Diamond J (1992) Crypt-villus site of glucose transporterinduction by dietary carbohydrate in mouse intestine. Am. J. Physiol. 262: G1069-GI073

Ferraris RP, Villenas SA and Diamond J (1992) Regulation of brush-border enzyme activities and enterocyte migration rates in mouse small intestine. Am. J. Physiol. 262: G1047-G1059
Frisch SM and Francis H (1994) Disruption of epithelial cell-matrix interactions induces apoptosis. J. Cell Biol. 124: 619-626

Gavrieli Y, Sherman Y and Ben-Sasson S (1992) Identification of programmed cell death in situ via specific labeling of nuclear DNA fragmentation. J. Cell Biol. 119: $493-501$

Gordon JI and Hermiston ML (1994) Differentiation and self-renewal in the mouse gastrointestinal epithelium. Curr. Opin. Cell Biol. 6: 795-803

Hall PA, Coates PJ, Ansari B and Hopwood D (1994) Regulation of cell number in the mammalian gastrointestinal tract: the importance of apoptosis. J. Cell Sci. 107: 3569-3577

Han H, Iwanaga T and Fujita T (1993) Species-differences in the process of apoptosis in epithelial cells of the small intestine: an ultrastructural and cytochemical study of luminal cell elements. Arch. Histol. Cytol. 56: 83-90

Hu Z, Yuri K, Ozawa H, Lu H and Kawata M (1997) The in vivo time course of elimination of adrenalectomy-induced apoptotic profiles from granule cell layer of the rat hippocampus. J. Neurosci. 17: 3981-3989

Iwanaga T, Hoshi O, Han H, Takahashi-Iwanaga H, Uchiyama Y and Fujita T (1994) Lamina propria macrofages involved in cell death (apoptosis) of enterocytes in the small intestine of rats. Arch. Histol. Cytol. 57: 267-276

Kerr JFR, Winterford CM and Harmon BV (1994) Apoptosis. Its significance in cancer and cancer therapy. Cancer 73: 2013-2025

Kerr JFR, Wyllie AH and Currie AR (1972) Apoptosis: a basic biological phenomenon with wide-ranging implications in tissue kinetics. Br. J. Cancer 26: 239-257

Kriss JP and Revesz L (1961) The distribution and fate of bromodeoxyuridine and bromodeoxycytidine in the mouse and rat. Cancer Res. 22: 254-265

Leblond CP and Messier B (1958) Renewal of chief cells and goblet cells in the small intestine as shown by radioautography after injection of thymidine- $\mathrm{H}^{3}$ into mice. Anat. Rec. 132: 247-259

Potten CS, Al-Barwari SE, Hume W and Searle J (1977) Circadian rhythms of presumptive stem cells in three different epithelia of the mouse. Cell Tissue Kinet. 10: $557-568$

Potten CS and Allen TD (1977) Ultrastructure of cell loss in intestinal mucosa. J. Ultrastruct. Res. 60: 272-277

Potten CS, Merritt A, Hickman J, Hall P and Faranda A (1994) Characterization of radiation-induced apoptosis in the small intestine and its biological implications. Int. J. Radiat. Biol. 65: 71-78

Raff MC, Barres BA, Burne JF, Coles HS, Ishizaki Y and Jacobson MD (1993) Programmed cell death and the control of cell survival: lessons from the nervous system. Science 262: $695-700$

Shibahara T, Sato N, Waguri S, Iwanaga T, Nakahara A, Fukotomi H and Uchiyama Y (1995) The fate of effete epithelial cells at the villus tips of the human small intestine. Arch. Histol. Cytol. 58: 205-219

Staley K, Blaschke AJ and Chun J (1997) Apoptotic DNA fragmentation is detected by a semiquantitative ligation-mediated PCR of blunt DNA ends. Cell Death Differ. 4: $66-75$

Vaux DL (1993) Toward an understanding of the molecular mechanisms of physiological cell death. Proc. Natl. Acad. Sci. USA 90: 786-789

Wright EM, Hirayama BA, Loo DDF, Turk E and Hager K (1994) Intestinal sugar transport. In: Physiology of the Gastrointestinal Tract Johnson LR, (ed) New York: Raven Press pp. 1751-1772

Wright $\mathrm{N}$ and Alison M (1984a) Cell lineage in the gastrointestinal tract. In: The Biology of Epithelial Cell Populations. Wright $\mathrm{N}$ and Alison M, (eds) Oxford: Clarendon Press pp. 551-598

Wright N and Alison M (1984b) The kinetic organization of gut epithelia. In: The Biology of Epithelial Cell Populations. Wright $\mathrm{N}$ and Alison M, (eds) Oxford: Clarendon Press pp. 688-742

Wright NA and Irwin M (1982) The kinetics of villus cell populations in the mouse small intestine. I. Normal villi: the steady state requirement. J. Tissue Kinet. 15: 595609

Wyllie AH, Morris RG, Smith AL and Dunlop D (1984) Chromatic cleavage in apoptosis: association with condensed chromatin morphology and dependence on macromolecular synthesis. J. Pathol. 142: 67-77 